\title{
The effect of duration of dependence and daily dose of tramadol in tramadol dependent patients on cognitive performance
}

\author{
Hossam Eddin Khalifa Ahmad ${ }^{1,2^{*}}$, Alaa Eldin Mohamed Darweesh', Shehab Hassan Mahmoud Hassaan', \\ Mostafa Nooman ${ }^{1}$, Islam Shaaban ${ }^{3}$ and Sayed Mostafa Sayed ${ }^{1}$
}

\begin{abstract}
Background: Tramadol dependence represents a major medical and legal hazardous phenomenon in the last decade. It is a synthetic opiate analgesic which exerts its therapeutic effect by its action on $\mu$ opioid receptors. It has a weak dependence ability. The present study investigated the effect of duration of dependence and daily dose of tramadol on cognitive performance. Cognitive functions were assessed using the following: the Mini-Mental State Examination (MMSE), the Montreal Cognitive Assessment (MoCA) test, Brief Visuospatial Memory Test-Revised (BVMT-R), Wechsler Adult Intelligence Scale-Third Edition (WAIS-III), the P300 (ERP), and conventional electroencephalogram.

Results: There was a non-significant negative correlation between the daily dose of tramadol and cognitive performance as regards IQ, Mini-Mental State Examination, MoCA score, P300 reaction time ( $\mu \mathrm{s})$, and deterioration index $(r=-0.08, P=0.689 ; r=-0.02, P=0.896 ; r=-0.11, P=0.554 ; r=-0.11, P=0.581, r=-0.17 ; P=0.368$, respectively). Additionally, the results showed non-significant negative correlation between the duration of dependence and the cognitive performance $(r=-0.19, P=0.325 ; r=-0.15, P=0.424 ; r=-0.30, P=0.108 ; r=-$ $0.02, P=0.909 ; r=-0.02, P=0.937$, respectively).
\end{abstract}

Conclusion: Daily dose and duration of tramadol dependence have a negative but non-significant effect on cognitive performance.

Keywords: Tramadol, Cognition, MMSE, IQ, MoCA, BVMT-R, P300 evoked potential

\section{Background}

Tramadol is a synthetic opioid analgesic first introduced in 1977 by the German pharmaceutical company Grunenthal as a pain killer that exhibits its analgesic effect through acting on $\mu$ opioid receptors by its $\mathrm{R}$ - and Ssterereoisomers [1]. It is as effective as codeine in pain relief and has only one tenth the analgesic effect of morphine on parenteral usage [2].

It has a weak dependence potentiality as was studied in many studies [3] with withdrawal manifestations

\footnotetext{
* Correspondence: hossamkhalifa71@Yahoo.com

${ }^{1}$ Assiut University Hospitals, Assiut, Egypt

${ }^{2}$ Faculty of Medicine, Assiut University, Assiut, Egypt

Full list of author information is available at the end of the article
}

similar to opioid withdrawal and atypical withdrawal symptoms in low percentage of patients [4]. Few studies investigated the effect of prolonged opioid abuse on cognitive functions [5-7].

\section{Hypothesis}

Prolonged or heavy abuse of tramadol as a partial opioid agonist acting mainly on $\mu$ receptors can produce more deterioration in cognitive functions.

\section{Study design}

Cross-sectional descriptive study that was performed at Assiut University Hospitals during the period from 1 March 2014 till 31 December 2014. 


\section{Patients and methods Patients}

Thirty tramadol-dependent patients from attendees at drug addiction outpatient clinic in Assiut University Hospitals participated in this study that ran between 1 March 2014 and 31 December 2014.

\section{Measurements}

The used cognitive battery included the Mini-Mental State Examination, the Montreal Cognitive Assessment scale, WAIS-III, Brief Visuospatial Memory Test-Revised, and P300 evoked potential.

\section{Mini-Mental State Examination}

It is a basic tool used to assess the cognitive functions [8]. The Mini-Mental State Examination (MMSE) is a brief one-page 30-point test administered in approximately $10 \mathrm{~min}$. It is used to assess the severity of cognitive impairment.

\section{Montreal Cognitive Assessment scale}

The Arabic version of the Montreal Cognitive Assessment (MoCA) is a prominent tool for the evaluation of minimal cognitive impairment (MCI) [9]. The MoCA test is a onepage 30-point test administered in approximately $10 \mathrm{~min}$. Normal MoCA score is above 25; for results less than 25, cognitive functions are considered to be affected.

\section{Brief Visuospatial Memory Test-Revised (BVMT-R)}

It was designed as an equivalent multiple test for assessment of visual memory. The test is used to evaluate the recall process and learning [10]. Two scores were calculated which are the discrimination index and the response bias and were included in the statistics of the study.

\section{The P300 wave of event-related potential}

The test was done using surpass EMS biomedical, quantitative EMG/EP workstation. The test was done through applying an odd-ball paradigm as the subject has to detect an occasional target stimulus in a train of regular "frequent" stimuli. The measured variables include P300 latency measured in milliseconds and the reaction time measured in microseconds. The normal latency is less than $300 \mathrm{~ms}$; latencies more than $300 \mathrm{~ms}$ are considered to be affected [11].

\section{Wechsler Adult Intelligence Scale}

The test includes a group of questions designed to evaluate both verbal and non-verbal IQ [12].

\section{Statistical tests}

Categorical variables were described in terms of number and percentage (no., \%). Continuous variables were described by mean and standard deviation (Mean, SD). A chi-square test was used to compare between categorical variables while a $t$-test was used to compare between continuous variables. Continuous variables for normally distributed data were tested using the KolmogorovSmirnov test and Q-Q plots. A two-tailed $P<0.05$ was considered statistically significant. All analyses were performed with the SPSS program version 20.0.

\section{Inclusion criteria}

1- Patients fulfill criteria for the diagnosis of tramadol use disorder based on DSM- 5 criteria.

2- No history of intake of other substances than tramadol in the last 12 months except for nicotine.

3- Proved to be negative for other substances by urine drug screen.

4- Male gender.

5- Age group between 18 and 45 years old.

\section{Exclusion criteria}

1- Patients meeting DSM-5 criteria for tramadolinduced intoxication or withdrawal.

2- Patients on regular medication known to affect the cognition, e.g., hypnotics.

3- Patients with chronic or serious medical disease that may affect the cognition, e.g., diabetes mellitus, hypertension, Parkinson's disease, and Huntington's disease.

4- Patients diagnosed with other co-morbid psychiatric disorders.

\section{Results}

\section{Socio-demographic characteristics}

The socio-demographic characteristics as presented in Table 1 show that the overall number of the individuals in the study group was 30 patients. The age of $63.3 \%$ of the study group was between 18 and 29 years and $36.7 \%$ was between 30 and 45 years. $66.7 \%$ were singles and $33.3 \%$ were married. Nearly half of the study sample were manual workers (43.3\%). Seventy percent belongs to the moderate socioeconomic level. Regarding the educational level, those who can read and write only were $43.3 \%$, illiterates $16.7 \%$, high school level $16.7 \%$, and university degree holders or above $23.3 \%$. $43.3 \%$ of them live in urban areas and $56.7 \%$ live in rural areas.

\section{The effect of the daily dose of tramadol on cognitive performance}

There was no significant difference in the mean scores of cognitive functions between patients receiving more than $1000 \mathrm{mg}$ per day and those receiving less than $1000 \mathrm{mg}$ : IQ $(P=0.635)$, MMSE $(P=0.097)$, MoCA $(P$ $=0.445)$, discrimination index $(P=0.365)$, response bias 
Table 1 The demographic characteristics of the studied sample

\begin{tabular}{|c|c|c|}
\hline & Case & \\
\hline & $\overline{\text { No. }}$ & $\%$ \\
\hline Age & & \\
\hline 18-29 years old & 19 & 63.3 \\
\hline 30-45 years old & 11 & 36.7 \\
\hline Marital status & & \\
\hline Single & 20 & 66.7 \\
\hline Married & 10 & 33.3 \\
\hline Residence & & \\
\hline Urban & 13 & 43.3 \\
\hline Rural & 17 & 56.7 \\
\hline Occupation & & \\
\hline Unemployed & 9 & 30.0 \\
\hline Student & 1 & 3.3 \\
\hline Manual work & 17 & 56.7 \\
\hline Office work & 3 & 10.0 \\
\hline Socioeconomic level & & \\
\hline High (> 145.69) & 2 & 6.7 \\
\hline Average (75.93-145.69) & 23 & 76.6 \\
\hline Low $(<75.93)$ & 5 & 16.7 \\
\hline Education & & \\
\hline Illiterate & 3 & 10.0 \\
\hline Read and write & 10 & 33.3 \\
\hline Intermediate & 13 & 43.3 \\
\hline University & 4 & 13.3 \\
\hline
\end{tabular}

$(P=0.402)$, and P300 latency $(P=0.117)$ (Table 2$)$. There was non-significant negative correlation between the daily dose of tramadol and the IQ mean score $(r=-$ $0.08, P=0.689)$, MMSE mean score $(r=-0.02, P=$ $0.896)$, MoCA mean score $(r=-0.11, P=0.554)$, discrimination index mean score $(r=-0.20, P=0.294)$, P300 latency $(r=-0.11, P=0.581)$, and reaction time $(r$ $=-0.17, P=0.368)$ (Table 3$)$.

\section{The effect of duration of tramadol dependence on cognitive performance}

The average of duration of dependence on tramadol among the patients in this study was 5.1 years with the percentage of subjects dependent on tramadol more than 5 years of $53.3 \%$. There was no significant difference in the
Table 3 Correlation between the daily dose of tramadol and the cognitive performance

\begin{tabular}{lll}
\hline & \multicolumn{2}{l}{ Daily dose } \\
\cline { 2 - 3 } & $r$ & $P$ value \\
\hline IQ & -0.08 & 0.689 \\
MMSE score & -0.02 & 0.896 \\
MoCA score & -0.11 & 0.554 \\
P300 latency & -0.11 & 0.581 \\
Reaction time ( $\mu$ s) & -0.17 & 0.368 \\
Deterioration index & 0.14 & 0.473 \\
Discrimination index & 0.20 & 0.294 \\
\hline
\end{tabular}

mean scores of cognitive functions between patients with more than 5 years of dependence and those with less than 5 years: IQ $(P=0.969)$, MMSE $(P=0.586)$, MoCA $(P=$ $0.345)$, discrimination index $(P=0.843)$, response bias $(P$ $=0.044)$, and P300 latency $(P=0.857)$ (Table 4). There was non-significant negative correlation between the daily dose of tramadol and the IQ mean score $(r=-0.19, P=$ 0.325), MMSE mean score $(r=-0.15, P=0.424)$, MoCA mean score $(r=-0.30, P=0.108)$, discrimination index mean score $(r=-0.09, P=0.826)$, P300 latency $(r=-$ $0.02, P=0.909)$, and reaction time $(r=-0.02, P=0.937)$ (Table 5).

\section{Discussion}

Few works studied the cognitive profile of tramadol dependence; however, many studies were done regarding the cognitive profile of other substances of abuse particularly the opioids and cannabis. This can be explained by that tramadol is not a very common drug in the western world and does not resemble a medical issue of importance regarding dependence to be a focus for the scientific research unlike in Egypt where it resembles a major health issue [13].

This study found no significant effect of heavy daily dose of tramadol on cognitive functioning; these results can be explained by the low affinity of tramadol and its metabolites particularly the most important one M1 to $\mu$ opioid receptors as shown in previous studies [14].

These results are consistent with the study of Minzter et al. [15] who studied the effect of two doses of tramadol, $200 \mathrm{mg} /$ day and $800 \mathrm{mg} /$ day, on cognitive performance

Table 2 Cognitive performance according to the daily dose of tramadol intake

\begin{tabular}{|c|c|c|c|c|c|c|}
\hline \multirow[t]{2}{*}{ Daily dose } & IQ & MMSE & MoCA score & Discrimination index & Response bias & P300 latency \\
\hline & Mean \pm SD & Mean \pm SD & Mean \pm SD & Mean \pm SD & Mean \pm SD & Mean \pm SD \\
\hline Dose $<1000 \mathrm{mg}$ & $86.9 \pm 8.7$ & $24.2 \pm 1.4$ & $22.7 \pm 1.7$ & $1.8 \pm 1.7$ & $0.5 \pm 0.1$ & $385.2 \pm 22.1$ \\
\hline Dose $>1000 \mathrm{mg}$ & $85.4 \pm 7.6$ & $25.3 \pm 1.6$ & $23.1 \pm 1.5$ & $2.3 \pm 1.4$ & $0.5 \pm 0.2$ & $366.4 \pm 31.4$ \\
\hline$P$ value & 0.635 & 0.097 & 0.445 & 0.365 & 0.402 & 0.117 \\
\hline
\end{tabular}


Table 4 Cognitive performance according to the duration of tramadol intake

\begin{tabular}{|c|c|c|c|c|c|c|}
\hline \multirow[t]{2}{*}{ Duration } & IQ & MMSE & MoCA score & Discrimination index & Response bias & P300 latency \\
\hline & Mean \pm SD & Mean \pm SD & Mean \pm SD & Mean \pm SD & Mean \pm SD & Mean \pm SD \\
\hline Duration $<5$ years & $85.8 \pm 9$ & $25.2 \pm 1.8$ & $23.3 \pm 1.5$ & $2.2 \pm 1.6$ & $0.6 \pm 0.2$ & $373.2 \pm 30.7$ \\
\hline Duration $>5$ years & $85.9 \pm 7.1$ & $24.8 \pm 1.5$ & $22.8 \pm 1.6$ & $2.1 \pm 1.5$ & $0.5 \pm 0.1$ & $371.2 \pm 30.1$ \\
\hline$P$ value & 0.969 & 0.586 & 0.345 & 0.843 & $0.044^{*}$ & 0.857 \\
\hline
\end{tabular}

*statistically significant

and found no statistical difference between the two groups.

This was also consistent with the findings of Carroll et al. [16] and Lofwall et al. [17] who studied the effect of two different daily doses, $50 \mathrm{mg} /$ day and $400 \mathrm{mg} /$ day, and found no difference in cognitive functions between the two groups.

Zacny and Goldman also found no significant effect of increasing the daily dose of propoxyphene (another opioid) on performance [18].

Regarding the effect of prolonged duration of tramadol dependence on cognitive performance, the results show no hazardous effect of prolonged dependence duration on cognitive functioning.

These results can be explained by the findings of Gillen et al. who found low potency and efficacy of tramadol and its metabolites particularly the most important one M1 on $\mu$ opioid receptors in comparison to naloxone or morphine [14].

These results are found to be consistent with the results of the work of Mintzer et al. which is, to our knowledge, the only work in literature up to date that studied the effect of repeated tramadol intake on cognitive performance and found no difference in psychomotor speed, attention, short-term memory, decision making, and working memory [15].

These findings are also consistent with the study of Sjogren et al. that found no significant correlation between the prolonged duration of administration of opioid analgesics and the worsening of cognitive performance [19].

Table $\mathbf{5}$ Correlation between the duration of tramadol dependence and the cognitive performance

\begin{tabular}{lll}
\hline & \multicolumn{2}{l}{ Duration } \\
\cline { 2 - 3 } & $r$ & $P$ value \\
\hline IQ & -0.19 & 0.325 \\
MMSE score & -0.15 & 0.424 \\
MoCA score & -0.30 & 0.108 \\
P300 latency & 0.02 & 0.909 \\
Reaction time $(\mu \mathrm{s})$ & -0.02 & 0.937 \\
Deterioration index & -0.14 & 0.454 \\
Discrimination index & -0.09 & 0.628 \\
\hline
\end{tabular}

\section{Conclusion}

Tramadol addiction has hazardous effects on cognitive functions mainly memory, attention, visuospatial functions, executive functions, decision making, and reaction time. The longer duration and the higher doses are nonsignificantly associated with more worsening of the cognitive functions.

\section{Abbreviations}

BVMT-R: Brief Visuospatial Memory Test-Revised; IQ: Intelligence quotation; MMSE: Mini-Mental State Examination; MoCA: Montreal Cognitive Assessment; WAIS-III: Wechsler Adult Intelligence Scale-Third Edition

\section{Acknowledgements}

Not applicable.

\section{Authors' contributions}

$A D, H K$, and $\mathrm{SH}$ designed the research, shared in the application of the cognitive tests, and analyzed the data. SM shared in the application of the cognitive tests. AD, HK, SH, and SM performed the biostatistical analyses. MN and IS supervised the research and shared in the data collection. AD, HK, and $\mathrm{SH}$ interpreted the data and wrote the paper draft. All authors have read and approved the manuscript.

\section{Funding}

The authors of this manuscript declare that no funding bodies were involved in sponsoring or funding this research, no grants were taken, and the research was conducted solely on the expense of the authors.

\section{Availability of data and materials}

The datasets generated during and/or analyzed during the current study are available from the corresponding author on reasonable request.

Ethics approval and consent to participate

The study was approved by the ethical committee of the Faculty of Medicine, Assiut University. All procedures followed were in accordance with the ethical standards of the responsible committee on human experimentation (institutional and national) and with the Helsinki Declaration of 1975, as revised in 2000. Informed consent was obtained from all patients for being included in the study.

Consent for publication

Not applicable

Competing interests

The authors declare that they have no competing interests.

Author details

${ }^{1}$ Assiut University Hospitals, Assiut, Egypt. ${ }^{2}$ Faculty of Medicine, Assiut University, Assiut, Egypt. ${ }^{3}$ Azhar University, Assiut, Egypt. 
Received: 27 June 2019 Accepted: 23 August 2019

Published online: 16 October 2019

\section{References}

1. Kupper RJ, Stumpf A (2003) Synthesis of (+/-)-2-

((dimethylaminomethyl)methyl)-1(aryl)cyclohexanols. (US 6,649,783 B2), pp $1-18$

2. Barkin RL (2008) Extended-release tramadol (ULTRAM ER): a pharmacotherapeutic, pharmacokinetic, and pharmacodynamic focus on effectiveness and safety in patients with chronic/persistent pain. Am J Ther 15(2):157-166

3. Radbruch L, Glaeske G, Grond S, Munchberg F, Scherbaum N, Storz E, Tholen K, Zagermann-Muncke P, Zieglgansberger W, Hoffmann-Menzel H, Greve H, Cremer-Schaeffer $P$ (2013) Topical review on the abuse and misuse potential of tramadol and tilidine in Germany. SubstAbus. 34(3):313-320

4. Senay EC, Adams EH, Geller A, Inciardi JA, Munoz A, Schnoll SH, Woody GE, Cicero TJ (2003) Physical dependence on Ultram (tramadol hydrochloride): both opioid-like and atypical withdrawal symptoms occur. Drug Alcohol Depend 69(3):233-241

5. Lu G, Zhou QX, Kang S, Li QL, Zhao LC, Chen JD, Sun JF, Cao J, Wang YJ, Chen J, Chen XY, Zhong DF, Chi ZQ, Xu L, Liu JG (2010) Chronic morphine treatment impaired hippocampal long-term potentiation and spatial memory via accumulation of extracellular adenosine acting on adenosine A1 receptors. J Neurosci 30:5058-5070

6. Chapman SL, Byas-Smith MG, Reed BA (2002) Effects of intermediate- and long-term use of opioids on cognition in patients with chronic pain. Clin J Pain. 18(4 Suppl):S83-S90

7. Schiltenwolf M, Akbar M, Hug A, Pfüller U, Gantz S, Neubauer E, Flor H, Wang H (2014) Evidence of specific cognitive deficits in patients with chronic low back pain under long-term substitution treatment of opioids. Pain Physician 17(1):9-20

8. Folstein MF, Folstein SE, PR MH (1975) "Mini-mental state". A practical method for grading the cognitive state of patients for the clinician. J Psychiatr Res 12(3):189-198

9. Benedict R (1997) Brief Visuospatial Memory Test-revised. Psychological Assessment Resources, Inc, Odessa, FL

10. Nasreddine ZS, Phillips NA, Bédirian V, Charbonneau S, Whitehead V, Collin I, Cummings JL, Chertkow H (2005) The Montreal Cognitive Assessment, MoCA: a brief screening tool for mild cognitive impairment. J Am Geriatr Soc. 53(4):695-699

11. Chapman RM, Bragdon HR (1964) Evoked responses to numerical and nonnumerical visual stimuli while problem solving. Nature 203:1155-1157

12. Wechsler D (1939) The measurement of adult intelligence. Williams \& Witkins, Baltimore (MD P.229

13. Abolmaged S, Kodera A, Okasha T, Gawad T, Rawson R (2013) tramadol use in Egypt: emergence of a new public health problem. CJA 4(1):5

14. Gillen C, Haurand M, Kobelt DJ, Wnendt S (2000) Affinity, potency and efficacy of tramadol and its metabolites at the cloned human $\mu$-opioid receptor. Naunyn-Schmiedeberg's Arch Pharmacol 362:116-121

15. Mintzer MZ, Lanier RK, Lofwall MR, Bigelow GE, Strain EC (2010) Effects of repeated tramadol and morphine administration on psychomotor and cognitive performance in opioid-dependent volunteers. Drug Alcohol Depend 111(3):265-268

16. Carroll CP, Walsh SL, Bigelow GE, Strain EC, Preston KL (2006) Assessment of agonist and antagonist effects of tramadol in opioid-dependent humans. ExpClinPsychopharmacol 14(2):109-120

17. Lofwall MR, Walsh SL, Bigelow GE, Strain EC (2007) Modest opioid withdrawal suppression efficacy of oral tramadol in humans. Psychopharmacology. 194:381-393

18. Zacny JP, Goldman RE (2004) Characterizing the subjective, psychomotor, and physiological effects of oral propoxyphene in non-drug-abusing volunteers. Drug Alcohol Depend 73(2):133-140

19. Sjogren P, Thomsen AB, Olsen AK (2000) Impaired neuropsychological performance in chronic nonmalignant pain patients receiving long-term oral opioid therapy. J Pain Symptom Manage. 19(2):100-108

\section{Publisher's Note}

Springer Nature remains neutral with regard to jurisdictional claims in published maps and institutional affiliations.

\section{Submit your manuscript to a SpringerOpen ${ }^{\odot}$ journal and benefit from:}

- Convenient online submission

- Rigorous peer review

- Open access: articles freely available online

High visibility within the field

- Retaining the copyright to your article

Submit your next manuscript at $\boldsymbol{\nabla}$ springeropen.com 